\title{
Consumer Perception of Selecting Brand: A Comparative Study between Pepsi Cola and Mojo Cola
}

\author{
Md. Kamal Hossain ${ }^{*}$, Subrata Kumar², Mohammad Ataur Rahman ${ }^{3}$
}

${ }^{1}$ Lecturer, Department of Business Administration, Pabna University of Science and Technology, Pabna, BANGLADESH

${ }^{2}$ Lecturer, Department of Business Administration, Central Women's University, Dhaka, BANGLADESH

${ }^{3}$ Senior Lecturer, Department of Business Administration, Central Women's University, Dhaka, BANGLADESH

*Corresponding Contact:

Email: hossain.kamal7523@gmail.com

Mobile: +8801718485775

\begin{abstract}
Consumers are so much conscious and sensitive in case of selecting brand .This study investigates the impact of consumer's perception in selecting beverage products between Pepsi cola \& Mojo cola. A survey was conducted by a significant number of respondents from the Pabna University of Science \& Technology \& surrounding areas. The data analyses were conducted by descriptive factor analysis, statistical tools \& technique. The results revealed that the most of the consumers are highly concerned about the perception of brand regarding selection of Pepsi cola \& Mojo cola beverage drinks. This is a relatively new issue that remains largely undiscovered by researchers under our country's perspective. It is hoped that the findings may assist the local (Akij Beverage Ltd.) and multinational (Transcom Beverage Ltd.) beverage companies about the necessities of enhancing their brand perception. The paper adds to the existing body of research on beverage consumers particularly on consumer's perceptions and expectations from these brands.
\end{abstract}

Key Words: Brand, Quality, Price, Influenced by Others, Advertising, Packaging, Customer Based Brand Equity Model

\section{INTRODUCTION}

Brand is a name, term, sign, symbol, or design, or combination of them, intended to identify the goods \& services of one seller or group of sellers to differentiate them those of competition (Keller). Consumer perception is the belief, perceived quality \& attitude towards the product. To identify the consumer perception of choosing soft drinks between foreign brand \& domestic brand, a foreign brand name Pepsi cola franchiser is Transcom Beverage \& a domestic brand Mojo of Akij Beverage Ltd. Soft drink is an important product item in modern society both urban and rural areas. Consumers mainly purchase the product for their refreshment. Gradually it is becoming more popular in the consumers' world and its demand 
is world- wide (Nuruzzaman, 1996). A soft drink is a beverage that does not contain alcohol or it is a non-alcoholic beverage typically containing water and a flavoring agent. The name "soft drink" specifies a lack of alcohol by way of contrast to the term "hard drink". The term "drink", while nominally neutral, sometimes carries connotations of alcoholic content. Beverages like colas, flavored water, sparkling water, iced tea, lemonade, squash, and fruit punch are among the most common types of soft drinks. Many carbonated soft drinks are optionally available in versions sweetened with sugars or with non-caloric sweeteners. Many of these beverages are carbonated and sweetened, and they may contain additional ingredients such as fruit juice. At present Bangladesh has a very competitive market of beverage. Bangladesh has a relatively hot weather and people tend to be thirstier. So they prefer to take soft drinks most of the time. Beverage took the market of Bangladesh in the first half of 1980. In that time two or three soft drinks were available in the market. But now lots of beverage found in the market. Some of them are popular and some are not so popular. Coca-Cola, Sprite, Pepsi are very famous drinks all over the world as well as Bangladesh. Mainly our young generation preferred to drinks. Now days there are many soft drinks company are coming continuously like Uro-Cola, RC Cola, Mojo, etc. After independence the food habit of Bangladeshi people has been changed a lot. Different foreign food companies were established in Bangladesh. Beverage industry is one of them. We will be engaged to measure the perception of brand choice between foreign brand Pepsi cola \& domestic brand Mojo Cola.

\section{JUSTIFICATION OF THE STUDY}

Due to the rapid changes in the global market and the increased competition experienced between firms, "Brand Management" has become more important. Good brand management brings about clear differentiation between products, ensures consumer loyalty and preferences and may lead to a greater market share. In the present scenario of Bangladesh, the competitions between the soft drinks increased very high. The companies are struggling a lot to keep up their market share in the industry and to improve the sales of their products because in the past there are few companies that are competing in the market. These companies are foreign franchise companies but with the passage of time domestic companies have also come in the market. Basically they are providing similar types of products to the consumers. For this the company has to know their position in the market and the opinion and loyalty of the customers when compared to their competitor. Because of this reason the comparative analysis is very important and useful to the Company. By the use of comparative analysis of perception of choosing brand between Pepsi cola \& Mojo companies, we can understand the position of the company and the strength and weaknesses of the company in the market. Through the comparative analysis we can understand that what strategies the competitors are using for the increase their sales volume. From the study we can gather the information regarding the opinion of the consumer on the companies comparatively and this will help to plans for the future to increase the performance of the company and to gain the loyalty of the customers when compared to their brands.

\section{OBjectives OF THE Study}

- To study the overview and present condition as well as various attributes which are played vital role on the perception between Mojo and Pepsi-Cola.

- To find out the differences between Mojo and Pepsi-Cola in terms of perceived quality of brand choice.

- To identify the opinions of the consumers about the preference or choice of soft drinks from other brands. 


\section{THEORETICAL FRAMEWORK}

Kotler et al (2010 p.549) defined a brand is "a name, term, sign, symbol, design or a combination of these that identifies the makers or seller of the product or services". This definition is based on the use of a brand name, symbols and signs to distinguish a product from its competitor. Prasad and dev (2000) noted that a brand can also be said to include all tangible and intangible attributes that the business stands for. According to Keller (2010 p.3), the American market association (AMA) defines a brand as a "name, term, sign, symbol or design or a combination of them, intended to identify the goods and services of one seller or group of sellers and to differentiate them from those of competitor" .

\section{Factors influencing consumer perceptions of a brand}

Kotler (2005) defined perception as the process by which information is received, selected, organised and interpreted by an individual. Some of the factors that influence consumer perceptions of a brand include:

Quality: This is one of the factors which consumers take into account when making their choice of brand. According to Uggla (2001), quality is an integrals part of brand identity.

Price: McDonald and Sharp (2000) stated that price can be used as a reason for brand choice in two ways; either by going for the lowest price in order to escape financial risk or the highest price in order to achieve product quality. According to soderlund (2000), price, place and brand are three important factors when deciding consumers purchase choice in everyday product.

Influence by others: According to Kotler et al (1999), influence by others plays a vital role in consumer's decision processes. Consumers have the habit of consulting each other regarding a new product or brand and seeking their advice.

Advertising: The main aim of advertisement is to create awareness. Advertisement is a conspicuous form of communication. According to Aaker (1991), if advertising, promotion and packaging embrace a regular positioning strategy over a period of time, there is the tendency that the brand will be strong. Some ways of reaching and communication to consumers through advertising is through television, cinema, radio, bill board etc.

Packaging: This is the process of designing the cover of a brand/product. According to Kotler et al (1991), packaging is a form of advertisement in the sense that it sales duties such as attracting consumers, describing and selling the product.

Convenience: according to Lin and Chang (2003), convenience of a brand has a significant effect on consumer. In other word, easy access to brand/product in store is vital when buying low involvement product.

\section{Customer Based Brand Equity Model}

"The differential effect that brand knowledge has on consumer response to the marketing of that brand". (Keller, et.al)

1. Salience: Related with- category identification \& need satisfied.

2. Performance: Related with- primary characteristics \& secondary features, product reliability, durability \& serviceability, service effectiveness, efficiency \& empathy, style \& design, price. 
3. Imagery: Related with- user profile, purchase \& usage situations, personality \&vales, history, heritage \& experience

4: Judgment: Related with- quality, credibility, consideration, superiority.

5. Feelings: Related with- warmth, fun, excitement, security, social approval, self respect.

6. Resonance: Related with- loyalty, attachment, community, engagement.

\section{LITERATURE REVIEW}

Deichert. et.al. (2006) in the study of "Strategic Management in a Global Context" describes the industry analysis of soft drinks. In that study, researchers researched about some economic factors that affect soft drink industry. Also researchers described five competitive forces of Coca Cola Company. In the magazine of Business 2000, the marketing of Sprite is described.

Luo (2006) in the study of "Factors influencing choosing brand" describes the influencing factors like brand name, brand image, price of the product which plays the vital role for selecting the soft drinks.

Three professors of East West University research on "A Study of the Factors used in Selecting Soft Drinks by the Bangladeshi Consumers", (Paper No. CB01). Its aim was to explore the factors used in selecting soft drinks by the Bangladeshi consumers. It also includes the comparison of the factors concerned between carbonated and non-carbonated soft drinks.

Hasan (2003) Perceptions of quality by consumers: A comparison between Coca cola \& Pepsicola beverages discussed on his MBA research. Researcher explained the issues in research on theoretical basis.

Hossain (2003) "An Evaluation of Brands Image, Product Attributes and Perceived Quality of a Selected Consumer Non-durable Product." In this study ten attributes are considered as important cues, which lead consumer to select a particular brand of soft drink. This study also examines products from a low involvement consumer product category.

Tong and Hawley (2009). "Measuring customer-based brand equity: Empirical evidence from the sportswear market in China" Journal of Product \& Brand Management. This study seeks to examine the practicality and applications of a customer-based brand equity model in the Chinese sportswear market.

Mahmud (2006). University of Dhaka researcher studied a research on "Brand competition: beverage industry of Bangladesh." In this study researcher described the nature of competition among the soft drinks of the beverage industry in Bangladesh. He also focused global companies are advantageous position than the domestic companies in Bangladesh.

Paracha, Waqas, Khan \& Ahmad (2012) “Consumer Preference Coca Cola versus PepsiCola" The primary purpose of this paper is to find out which company is leading the market. This research required to conduct the consumer research on why they chose the drink. To find out the factors \& reasons that influence to choose their preferred drink.

Ukpebor \& Ipogah (2008) "A Study to Indicate the Importance of CONSUMER BASEDBRAND EQUITY on Consumer Perception of Brand" This thesis focuses on the importance of these dimensions (brand awareness, brand loyalty, brand image and perceived quality) of customer-based brand equity on consumer's perceptions of a brand. This is based on the assumption that all these dimensions of customer based-brand equity will have influence on consumer's perceptions of brand. 
Josep-Francesc (Spain), María (Spain), Raquel (Spain) (2011) “Consumer perception towards brands in times of great price sensitivity" This article examines the appeal brands maintain for consumers in light of the new consumption paradigm towards the soft drinks.

Oyeniyi (2009) "Analysis of Nigerian Consumers' Perception of Foreign Soft Drinks" This article presents the results of a survey of Nigerian consumers' perception and attitude towards foreign soft drinks Products. The focus of the study is the source of information in evaluating a soft drinks product; the evaluation of specific soft drinks dimensions used by Nigerian consumers in their assessment of different soft drinks product categories.

\section{Methodology}

Methodology may be a description of process, or may be expanded to include a philosophically coherent collection of theories, concepts or ideas as they relate to a particular discipline or field of inquiry. It may refer to nothing more than a simple set of methods or procedures, or it may refer to the rationale and the philosophical assumptions that underlie a particular study relative to the scientific method. For this study we will use "customer based brand equity model" to identify the customer evaluation on choice of brand.

Our target population was the people who drink soft drinks. Our entire population is segregated into two groups- Students \& other peoples these sample units from which sample elements is collected. We collected data over 200 samples and as a method "Purposive Sampling" is used for selecting sample elements. Here divided our entire population into 2 groups and samples are picked up from these stratums on snowball or convenience basis.

Both the primary and secondary data is collected.

Primary sources: Primary data is collected through questionnaires, face to face conversation with people, face-to-face conversation and in depth interview with the respective persons.

Secondary sources: Secondary data have been collected from different books, journals, and magazines, internet, newspapers \& related articles, press release etc.

\section{FINDINGS AND ANALYSIS}

As satisfying trust consumer perception regarding Pepsi cola is positive because $96 \%$ has Excellent, Very Good \& Good response. On the other hand satisfying trust consumer perception regarding Mojo cola is also positive because $72 \%$ has Excellent, Very Good \& Good response. Though these two has positive response, Pepsi cola is more favorable to customers than Mojo cola in this aspect. That serves our first objective.

Consumer perception about Pepsi cola regarding attributes is positive because $84 \%$ has Excellent, Very Good \& Good response. On the other hand Consumer perception about Mojo cola regarding attributes is also positive because $68 \%$ has Excellent, Very Good \& Good response. Though these two has positive response, Pepsi cola is more favorable to customers than Mojo cola in this aspect. That serves our first objective.

Consumer perception about Pepsi cola regards providing the basic functions is positive because $88 \%$ has Excellent, Very Good \& Good response. On the other hand Consumer perception about Mojo cola regards providing the basic functions is also positive because 56\% has Excellent, Very Good \& Good response. Considering it with Pepsi cola \& other brand is not so good in this aspect. That serves our third objective. 
Consumer perception about Pepsi cola regarding product quality is positive because $88 \%$ has Excellent, Very Good \& Good response. On the other hand Consumer perception about Mojo cola regarding product quality is also positive because $64 \% \%$ has Excellent, Very Good \& Good response. Though these two has positive response, Pepsi cola is more favorable to customers than Mojo cola in this aspect. That serves our second objective.

Consumer perception about Pepsi cola regarding feelings is positive because $88 \%$ has Excellent, Very Good \& Good response. On the other hand Consumer perception about Mojo cola regarding feelings is also positive because $72 \%$ has Excellent, Very Good \& Good response. Though these two has positive response, Pepsi cola is more favorable to customers than Mojo cola in this aspect. That serves our first objective.

Consumer perception about Pepsi cola regarding selecting brand is positive because $92 \%$ has Excellent, Very Good \& Good response. On the other hand Consumer perception about Mojo cola regarding selecting brand is also positive because $76 \%$ has Excellent, Very Good \& Good response. Though these two has positive response, Pepsi cola is more favorable to customers than Mojo cola in this aspect. That serves our third objective.

Consumer perception about Pepsi cola regarding influence of advertisement to choose cola product is positive because $80 \%$ has Excellent, Very Good \& Good response. On the other hand Consumer perception about Mojo cola regarding influence of advertisement to choose cola product is also positive because $76 \%$ has Excellent, Very Good \& Good response. Though these two has positive response, Pepsi cola is more favorable to customers than Mojo cola. That serves our third objective.

Consumer perception about Pepsi cola regarding price is positive because $68 \%$ has Excellent, Very Good \& Good response. On the other hand Consumer perception about Mojo cola regarding price is also positive because $64 \%$ has Excellent, Very Good \& Good response. Though these two has positive response, Pepsi cola is more favorable to customers than Mojo cola in this aspect. That serves our second objective.

Consumer perception about Pepsi cola regarding society permit is positive because $58 \%$ has Excellent, Very Good \& Good response. On the other hand Consumer perception about Mojo cola regarding price is also positive because $60 \%$ has Excellent, Very Good \& Good response. Though these two has positive response, Mojo cola is more favorable to customers than Pepsi cola in this aspect. That serves our first objective.

Consumer perception about Pepsi cola regarding influence of Media is positive because $88 \%$ has Excellent, Very Good \& Good response. On the other hand Consumer perception about Mojo cola regarding price is also positive because $80 \%$ has Excellent, Very Good \& Good response. Though these two has positive response, Pepsi cola is more favorable to customers than Mojo cola in this aspect. That serves our third objective.

Consumer perception about Pepsi cola regarding Personality \& value perception is positive because $72 \%$ has Excellent, Very Good \& Good response. On the other hand Consumer perception about Mojo cola regarding Personality \& value perception is also positive because $68 \%$ has Excellent, Very Good \& Good response. Though these two has positive response, Pepsi cola is more favorable to customers than Mojo cola in this aspect. That serves our second objective.

Consumer perception about Pepsi cola regarding role of marketing to identify the brand is positive because $88 \%$ has Excellent, Very Good \& Good response. On the other hand 
Consumer perception about Mojo cola regarding role of marketing to identify the brand is also positive because $72 \%$ has Excellent, Very Good \& Good response. Though these two has positive response, Pepsi cola is more favorable to customers than Mojo cola in this aspect. That serves our first objective.

Consumer perception about Pepsi cola regarding Reputation is positive because $80 \%$ has Excellent, Very Good \& Good response. On the other hand Consumer perception about Mojo cola regarding Reputation is also positive because $76 \%$ has Excellent, Very Good \& Good response. Though these two has positive response, Pepsi cola is more favorable to customers than Mojo cola in this aspect. That serves our second objective.

Consumer perception about Pepsi cola regarding availability does play role to prefer to choose the brand is positive because $92 \%$ has Excellent, Very Good \& Good response. On the other hand Consumer perception about Mojo cola regarding availability does play role to prefer to choose the brand is also positive because $72 \%$ has Excellent, Very Good \& Good response. Though these two has positive response, Pepsi cola is more favorable to customers than Mojo cola in this aspect. That serves our third objective.

Consumer perception about Pepsi cola regarding impact of Social status is positive because $76 \%$ has Excellent, Very Good \& Good response. On the other hand Consumer perception about Mojo cola regarding impact of Social status is also positive because $64 \%$ has Excellent, Very Good \& Good response. Though these two has positive response, Pepsi cola is more favorable to customers than Mojo cola in this aspect. That serves our second objective.

Consumer perception about Pepsi cola regarding influence of environment is positive because $80 \%$ has Excellent, Very Good \& Good response. On the other hand Consumer perception about Mojo cola regarding influence of environment is also positive because $76 \%$ has Excellent, Very Good \& Good response. Though these two has positive response, Pepsi cola is more favorable to customers than Mojo cola in this aspect. That serves our second objective.

Consumer perception about Pepsi cola regarding satisfying need is positive because $80 \%$ has Excellent, Very Good \& Good response. On the other hand Consumer perception about Mojo cola regarding satisfying need is also positive because $68 \%$ has Excellent, Very Good \& Good response. Though these two has positive response, Pepsi cola is more favorable to customers than Mojo cola in this aspect. That serves our second objective.

Overall perception of selecting Brand between Pepsi cola \& Mojo cola

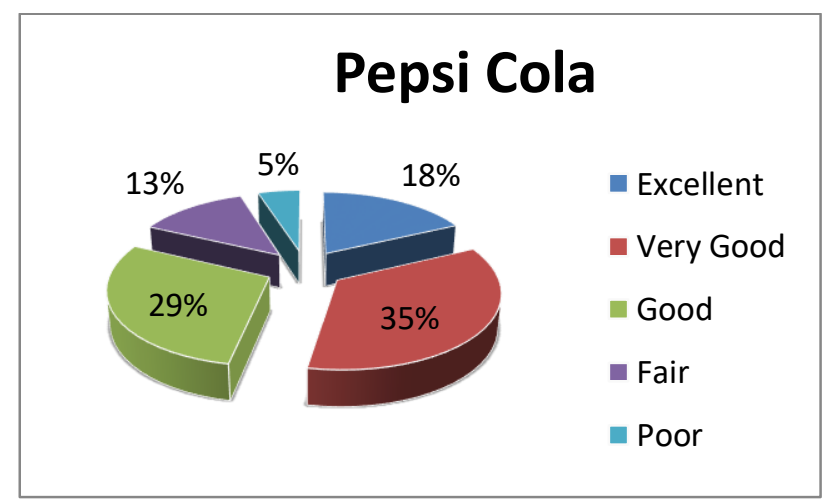

Pepsi cola overall perception of selecting Brand Excellent 18\%, Very Good 35\%, Good 29\%, Fair 13\%, Poor 5\%. 


\section{Mojo Cola}

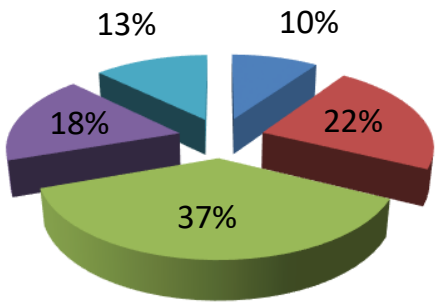

Excellent

Very Good

Good

Fair

Poor

Mojo cola overall perception of selecting Brand Excellent 10\%, Very Good 22\%, Good 37\%, Fair $18 \%$, Poor $13 \%$.

Findings of customer based brand equity model elements analysis in comparison to Pepsi cola \& Mojo cola in terms of positive attitude.

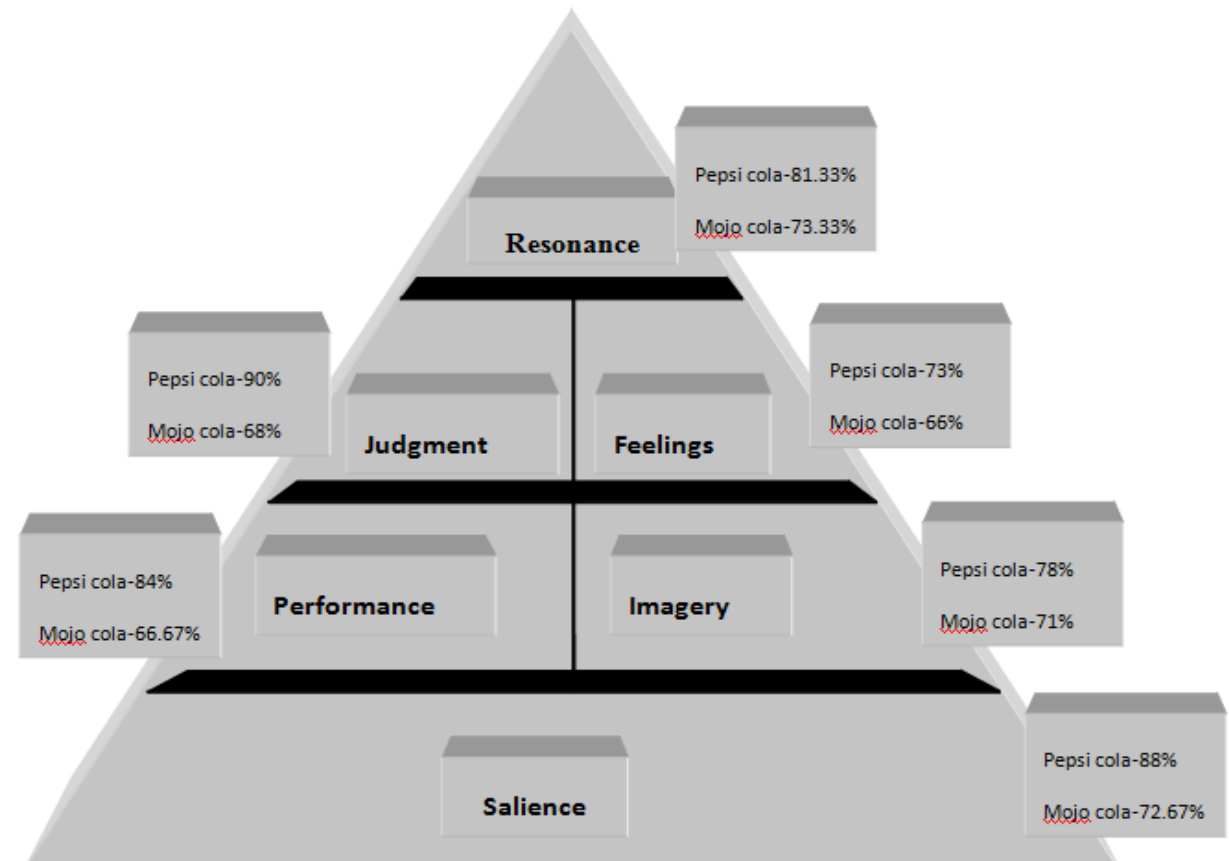

Fig: Customer Based Brand Equity Model

\section{RECOMMENDATIONS}

There is no significant difference between Pepsi cola and Mojo cola in terms of the perception of selecting brand in advertisement, price influence, personality \& value perception, society permit, reputation, environmental factors according to the findings of data analysis. In fact, it is proved that Pepsi cola and Mojo cola are all but same in the mind of consumer in terms of these issues. On the basis of satisfying brand, social status, marketing effort, media influence a little bit difference has been found between Pepsi cola and Mojo cola. These perceptions of Pepsi-Cola are better than Mojo cola according to the findings of data analysis. On the other hand availability, 
satisfying thirst, attributes, functional ability, quality, feelings, brand these situations have significant differences between Pepsi cola \& Mojo cola. These perceptions of Pepsi cola are much better than Mojo cola according to the findings of data analysis.

The overall perception of consumer's on Pepsi-Cola is better than the overall perception of consumer's on Mojo-Cola according to the findings of data analysis. That means, the attitude of consumer is much better regarding availability, satisfying thirst, attributes, functional ability, quality, feelings, brand these situations in terms of selecting Pepsi cola.

Although there are some limitations in this study nevertheless it can help the top management and others for making good policies and formulation strategies regarding the perception of selecting the cola product. The recommendations given below are not decisions; rather they are only suggestions to improve the customer's perception towards brand Pepsi cola \& Mojo cola. The recommendations are given below:-

- Consumer perception of selecting brand as Pepsi cola in terms of availability, quality, as a brand reputation comparison to other is very high or satisfactory but perception of Mojo cola is good but not high as Pepsi cola. So it has to emphasize on availability, quality, establishing brand reputation etc. to achieve good market share. On the other hand Pepsi Cola Company must have to sustain these issues.

- Consumer attitude towards Pepsi cola about satisfying feelings, product quality, fulfilling basic function is very high or satisfactory than the Mojo cola. So it's company has must be aware of these issues to attract consumers. On the other hand Pepsi Cola Company must have to sustain these issues.

- Marketing abilities \& media performance is very helpful for sustaining in the market for longer period of time. Its appeal is satisfactory to the consumers in terms of Pepsi cola rather than the Mojo cola. So the producer of Mojo cola should develop marketing abilities \& media performance. On the other hand Pepsi Cola Company must have to sustain these issues.

- Consumer attitude towards Pepsi cola about satisfying needs is very high so Mojo Cola Company has to concern this issue. Otherwise they have to face adverse situation.

- Pricing is a vital issue for growing perception towards a brand both the brand has comparatively same attitude to the customers so these company must have to be careful in pricing strategy.

- As a domestic brand Mojo cola gets more social benefit than the Pepsi cola. So social involvement with the community must be improved.

- Environment influence much more to select Mojo cola than Pepsi cola. Environmental consideration should be taken by the producer of Pepsi Cola Company.

\section{REFERENCES}

Agarwal, M.K. \& Rao, V.R. (1996). “An Empirical Comparison of Consumer-Based Measures of Brand Equity." Marketing Letters, 7(3), pp. 237- 247.

Ahmed, J., \& Rouf, M. (2014). Controlled, Uncontrolled Communication, Brand Name and Brand Attitude: A Relational Study on Cellular Telecom Sector of Bangladesh. American Journal Of Trade And Policy, 1(3), 102 - 108.

Alam, N., \& Rubel, A. (2014). Impacts of Corporate Social Responsibility on Customer Satisfaction in Telecom Industry of Bangladesh. ABC Journal Of Advanced Research, 3(2), 26 - 37.

Atilgan. E, Aksoy S. and Akinci S. (2005). "Determinants of the Brand Equity: A Verification Approach in the Beverage Industry in Turkey." Marketing Intelligence and Planning, 23(2/3), pp. 237-248.

Bijuna C. Mohan (March 2016), "The impact of customer-based brand equity on the operational performance of FMCG companies in India." Volume 28, Issue 1, Pages 13-19.

Burmann,C., Jost-Benz, M. \& Riley, N. (2009), “Towards An Identity-Based Brand Equity Model." Journal of Business Research, 62(1), pp. 390 - 397. 
Charumbira, L. (2015). Perceived Brand Equity in Professional Sports Teams: A Zimbabwean Consumers'Perspective. Asian $\quad$ Business 131-140. doi:http:/ / dx.doi.org/10.18034/abr.v5i3.660

Chile, L., \& Talukder, D. (2014). The Paradox of Agricultural Trade Liberalization in Bangladesh and Tanzania.American Journal Of Trade And Policy, 1(1), 23 - 31.

Chowdhury, M., \& Rahman, M. (2015). Consumer Attitude Towards the Cell Phone: A study on Young Generations of Chittagong Metropolitan City, Bangladesh. Asian Business Review, 3(3), 16-20. doi:http://dx.doi.org/10.18034/abr.v3i3.290

Con Kevin Lane Keller (Jan. 1993) “Conceptualizing, Measuring, and Managing Customer-Based Brand Equity" Journal of Marketing Vol. 57, No. 1, pp. 1-22.

Fatema, M., Azad, M., \& Masum, A. (2015). Impact of Brand Image and Brand Loyalty in Measuring Brand Equity of Islami Bank Bangladesh Ltd.. Asian Business Review, 2(1), 42-46. doi:http://dx.doi.org/10.18034/abr.v2i1.314

Hafiz, R. (2015). Rethinking Brand Identity to Become an Iconic Brand - A Study on Pepsi. Asian Business Review, 5(3), 97-102. doi:http://dx.doi.org/10.18034/abr.v5i3.585

Hossain Md. Enayet (2007) “An Evaluation of Brands Image, Product Attributes and Perceived Quality of a Selected Consumer Non-durable Product." Administration and Management Review Vol. 19, No. 2, Special Issue pp. 47-63.

Josep-Francesc Valls (Spain), María Jose Andrade (Spain), Raquel Arribas (Spain) (2011) "Consumer perception Towards brands in times of great price sensitivity" Innovative Marketing, Volume 7, Issue 2.

Kotler, Keller \& et al. (2007). "Marketing Management: A South Asian Perspective." (12th edition), Pearson Prentice Hall, New Delhi, India. p. 257.

Mahmud S, (2006). University of Dhaka studied a research on "Brand competition: Beverage Industry of Bangladesh.

Malhotra K Naresh, Marketing Research an Applied Orientation, 4th edition.

Meghan Deichert,et.al. (2006) in the study of "Strategic Management in a Global Context.

Oyeniyi O (2009) "Analysis of Nigerian Consumers' Perception of Foreign Soft Drinks"

Paracha A M J, Waqas M, Khan A R \& Ahmad S (2012) “Consumer Preference Coca Cola Versus Pepsi-Cola"

R. Kenneth Teas (Oct.1993) "Expectations, Performance Evaluation, and Consumers' Perceptions of Quality." Journal of Marketing Vol. 57, No. 4, pp. 18-34.

R. Shashikala, A. M. Suresh (March 2013) "Measuring Customer Based Brand Equity Using Aaker's Model" Volume 43, Issue 3.

R. Kenneth Teas Sanjeev Agarwal "The effects of extrinsic product cues on consumers' perceptions of quality, sacrifice, and value" Journal of the Academy of Marketing research, March 2000, Volume 28, Issue 2, pp 278-290.

Salehe, M., Luomba, J., Musiba, M., Mlaponi, E., \& Mghamba, K. (2014). Consumer Preference on Value Added Products of Farmed Fish in Lake Victoria Basin, Tanzania. Asian Journal Of Applied Science And Engineering, 3(4), 396-401.

Tong, X. and Hawley, J.M.(2009). “Measuring customer-based brand equity: Empirical Evidence from the sportswear market in China"

Ukpebor P \& Ipogah B (2008) “A Study to Indicate the Importance of Consumer Based Brand Equity on Consumer Perception of Brand"

Valarie A. Zeithaml (July 1988) "Consumer Perceptions of Price, Quality, and Value: A Means-End Model and Synthesis of Evidence". Journal of Marketing Vol. 52, No. 3. pp. 2-22.

Xueling Luo, (2006) in the study of "Factors influencing choosing brand".

--0-- 